\title{
SIR GEORGE F. HARDY
}

In opening the Meeting of the Faculty held on 16th November. the President (Mr. Hutton) said :-Before calling upon the Secretary to read Mr. Moir's paper I feel that I must refer to the great loss which our profession has suffered through the death of Sir George Hardy. You will remember that on the occasion of our meeting last June we endeavoured to express to Sir George our appreciation of his professional and public services, and our admiration for his personal gifts by electing him an Honorary Fellow of the Faculty. That position he honoured us by accepting, and it is a matter of great regret that we have not had the privilege of knowing Sir George more intimately, which we had hoped might have followed from his election. Your Council at its latest meeting passed the following resolntion :-

' It was resolved to place on record the deep regret with which the Council had learned of the death of Sir George Francis Hardy, K.C.B., a past President of the Institute of Actuaries, and an Honorary Fellow of the Faculty of Actuaries in Scotland.

"Throughout his lifetime he devoted his brilliant gifts in large measure to the enrichment of Actuarial Science, and his influence will long survive him not only in the record of his work, which forms so indispensable a part of Actuarial knowledge and remains an invaluable possession, but also in the inspiration he has been to so many of a younger generation of Actuaries. The charm of his personality endeared him to a wide circle of friends who mourn his loss and cherish his memory in sincere affection.

"The Council desired to offer to Lady Hardy an expression of their most sincere sympathy, and instruct the Honorary Secretary to forward to her a copy of this minute."

We have received grateful acknowledgment from Lady Hardy, and I am sure that the action of your Council will meet with your warm approval. 